\title{
RETRACTION
}

DOI: $10.3892 /$ etm.2018.6179

\section{Recent perspectives of pediatric mitochondrial diseases}

\section{JUNHUA CAO, HONGWEI WU and ZHENGUANG LI}

Exp Ther Med 15: 13-18, 2018; DOI: 10.3892/etm.2017.5385

Following the publication of this review, an interested reader drew to our attention that its text had been misappropriated to a large extent from a doctoral thesis written by Dr Karin Naess at the Karolinska Institutet, Stockholm, Sweden, which had appeared online ["Mitochondrial disease in children: from clinical presentation to genetic background", Naess K, published online January 13 2017].

Following an internal enquiry, the Editor of Experimental and Therapeutic Medicine has decided that the claim made by the interested reader should be upheld; therefore, the Editorial Board have decided to retract the above review from the publication. Independently of our having received this notification, the authors themselves contacted the office to request the retraction of their review due to an undeclared conflict of interest on their part. Note that, although the authors concerned all agree to the retraction of this review, their agreement to this retraction was only based on an undeclared conflict of interest. The Editor apologizes to the readership of the Journal for any inconvenience caused. 